\title{
The histidine utilization (hut) genes of Pseudomonas fluorescens SBW25 are active on plant surfaces, but are not required for competitive colonization of sugar beet seedlings
}

\author{
Xue-Xian Zhang, ${ }^{1,2,3}$ Andrew George, ${ }^{1}$ Mark J. Bailey ${ }^{2}$ \\ and Paul B. Rainey ${ }^{1,3}$ \\ ${ }^{1}$ Department of Plant Sciences, University of Oxford, South Parks Road, Oxford OX1 3RB, UK \\ ${ }^{2}$ Center for Ecology and Hydrology NERC, Mansfield Road, Oxford OX1 3SR, UK \\ ${ }^{3}$ School of Biological Sciences, University of Auckland, Private Bag 92019, Auckland, \\ New Zealand
}

Correspondence

Xue-Xian Zhang

xx.zhang@auckland.ac.nz

Received 30 November 2005

Revised 11 February 2006

Accepted 22 February 2006

\begin{abstract}
The ability to monitor the spatial and temporal distribution of signals in complex environments is necessary for an understanding of the function of bacteria in the wild. To this end, an existing recombinase-based transcriptional reporter strategy (recombinase-based in vivo expression technology, RIVET) has been extended and applied to the plant-colonizing bacterium Pseudomonas fluorescens SBW25. Central to the project was a rhizosphere-inducible locus, rhi14, which functional analyses show is hut $T$, a histidine-inducible gene that is required for histidine utilization. A transcriptional fusion between hutT and a promoterless site-specific recombinase $\left(t n p R^{\text {mut168}}\right)$ results in excision of a chromosomally integrated tetracycline-resistance cassette in a histidine-dependent manner. The dose- and time-responsiveness of the promoterless recombinase to histidine closely mirrored the histidine responsiveness of an identical hut $T$ fusion to promoterless lacZ. To demonstrate the effectiveness of the strategy, the activity of hutT was monitored on sugar beet seedlings. Low levels of transcriptional activity were detected in the phyllosphere, rhizosphere and in plant extract, but not in vermiculite devoid of seedlings. The histidine concentration in the rhizosphere was estimated to be $0.6 \mu \mathrm{g} \mathrm{ml}^{-1}$. The ecological significance of the hut locus was examined by competing a hutT deletion mutant against the wild-type during colonization of sugar beet seedlings. No impact on competitive fitness was detected, suggesting that the ability to utilize plant-derived histidine is not essential for bacterial colonization.
\end{abstract}

\section{INTRODUCTION}

Bacteria continually alter patterns of gene expression in order to optimize fitness. In complex environments, insight into the moment-by-moment changes in levels of transcription can reveal a great deal about both the genetic and the physiological response of bacteria to their environment and the nature of the environment itself (Merrell \& Camilli, 2000; Rainey \& Preston, 2000; Lindow \& Brandl, 2003).

Our long-term goal is to determine the contribution of individual Pseudomonas fluorescens genes to ecological

\footnotetext{
Abbreviations: CFC, cetrimide, fucidin and cephalosporin; IVET, in vivo expression technology; Km, kanamycin; Pc, pipercillin; RBS, ribosomebinding site; RIVET, recombinase-based IVET; SOE-PCR, splicing by overlapping extension using the polymerase chain reaction; Tc, tetracycline.
}

performance (fitness) in the wild (Rainey, 1999; Preston et al., 2001; Gal et al., 2003; Zhang et al. 2004a, b). A first step has been to devise and exploit a genetic strategy that identifies $P$. fluorescens genes that show elevated levels of transcription in the plant rhizosphere (rhi genes; Rainey, 1999; Gal et al., 2003). These rhigenes are of interest because they are predicted to play a role in the maximization of ecological performance, a prediction recently confirmed for a locus encoding an acetylated cellulose polymer (Gal et al., 2003; Spiers et al., 2003).

Testing this prediction is in principle straightforward. Typically, it involves the generation of defined rhi mutants, which are competed directly with an isogenic wild-type ancestor in the rhizosphere, the ratio of the Malthusian parameters providing a precise measure of the fitness of the mutant relative to the wild-type (Lenski, 1991; Gal et al., 2003). But an important consideration in such analyses is the 
heterogeneity of the environment. In a complex environment such as the plant rhizosphere, accurate assessment of the contribution of individual genes to ecological performance requires knowledge of environmental heterogeneity, and especially the spatial and temporal distribution of inducing signals. At present this is not easily achieved. A variety of transcriptional reporters exist, but these tend to yield data that are either too low in resolution (for example, population-level assays based on gene fusions to transcriptional reporters such as 'lacZ or 'uidA), or too high in resolution (for example, single-cell analysis of ' $g f p$ expression) to be generally useful. While the analysis of gene expression at the single-cell level is desirable, attempts to determine where and when a particular gene is activated by microscopic analysis of individual cells in a complex 'dirty' environment like the rhizosphere can be 'a needle in a haystack' exercise. We note, however, that $g f p$ fusions have been successfully used to study the response of individual bacterial cells to signals in the phyllosphere (Brandl et al., 2001; Leveau \& Lindow, 2001). Of use would be strategies to obtain information on specific environmental signals with a resolution between that of population-based assays and that of single-cell reporters such as $g f p$.

A modification to the in vivo expression technology (IVET) strategy, the recombinase-based IVET (RIVET), provides a possible way forward. RIVET was originally designed to identify infection-induced genes in Vibrio cholerae (Camilli et al., 1994; Camilli \& Mekalanos, 1995). It relies on a reporter gene $(\operatorname{tnpR})$ that encodes a site-specific DNA recombinase and an unlinked antibiotic-resistance gene cassette flanked by recombinase recognition sequences (res1). When expressed, the recombinase catalyses the excision of the antibiotic-resistance gene, and the permanent loss of antibiotic resistance acts as a heritable reporter of gene expression. RIVET therefore has the power to detect transiently expressed genes and to monitor gene expression in a small bacterial population. The ability of RIVET to report gene activity in situ was shown by Lee et al. (1999), who used it to study spatial and temporal induction of specific $V$. cholerae genes in a mouse model. Bacteria were harvested from specific organs at predetermined times and evidence of gene induction was obtained simply from the ratio of tetracycline-sensitive to tetracycline-resistant cells. Recombinase strategies have also been described for the study of toluene and arabinose availability in plant-colonizing Enterobacter cloacae JL1157 and P. fluorescens A506 (Casavant et al., 2002, 2003). Here we describe the development and application of RIVET to $P$. fluorescens SBW25. Integral to this task was a functional analysis of a previously uncharacterized rhi fusion (rhi14) (Rainey, 1999) that we show is both histidine inducible and required for histidine utilization. We show that RIVET is able to report, at the single-cell level, the transcriptional activity of the histidine uptake and degradation operon $(h u t)$ in the plant environment, that low levels of histidine are present in the plant environment and that histidine utilization is not a major determinant of ecological performance in planta.

\section{METHODS}

Bacterial strains and growth conditions. Bacterial strains and plasmids used in this study are listed in Table 1. Escherichia coli strains were grown on Luria-Bertani (LB) medium (Sambrook et al., 1989 ) at $37^{\circ} \mathrm{C}$. P. fluorescens SBW25 and its derivatives were grown at $28^{\circ} \mathrm{C}$ in LB or minimal medium M9 (Sambrook et al., 1989). Where appropriate, antibiotics were added to the following concentrations $\left(\mu \mathrm{g} \mathrm{ml}^{-1}\right)$ : streptomycin $(\mathrm{Sm}), 100$; tetracycline $(\mathrm{Tc}), 10$; pipercillin $(\mathrm{Pc}), 150$; kanamycin $(\mathrm{Km}), 50$. M9 plates containing half-strength CFC (cetrimide, fucidin and cephalosporin) supplement from Oxoid were used to select for $P$. fluorescens recovered from the phytosphere of sugar beet.

DNA manipulations. Plasmid DNA was extracted using the Qiagen miniprep extraction kit. DNA restriction and modification enzymes and T4 DNA ligase (New England Biolabs) were used according to the manufacturer's protocol. DNA fragments from agarose gels were extracted and purified using the Qiagen QIAquick Gel Extraction kit. All oligonucleotide primers (Table 1) were obtained from MWG Biotech. PCR reactions using Taq DNA polymerase (Qiagen) were performed according to the manufacturer's protocol with an annealing temperature of $58^{\circ} \mathrm{C}$. DNA was sequenced using the BigDye Terminator Sequencing kit (Applied Biosystems) on an Automated DNA Sequencer, model 310 (Perkin Elmer).

Plasmid and strain construction. To integrate the res1-tet-res1 cassette into the SBW25 genome, a previously described two-step allelic exchange method was used (Gal et al., 2003). The delivery plasmid pIVET-Tc4 was constructed by placing the res1-tet-res 1 cas-

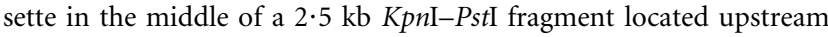
of the well-characterized wss operon (Spiers et al., 2002). The KpnIPstI fragment had been previously cloned into pBluescript $\left(\mathrm{SK}^{+}\right)$. The resulting plasmid (pAS232) contained a unique HindIII site in the middle of the insert between a truncated ORF of $f a b G$ and tRNA $^{\text {Thr }}$ (Spiers et al., 2002). The resl-tet-resl cassette (a $3.6 \mathrm{~kb}$ KpnI-PstI fragment from pGH436) was cloned into pAS232, which was digested with HindIII and blunt-ended with the Klenow fragment of DNA polymerase. The whole insert was then PCR-amplified using the general M13 forward and reverse primers containing SpeI restriction sites. To generate the final delivery plasmid pIVET-Tc4, the PCR products were cloned onto the unique SpeI site of pIVETP1, a derivative of the IVET vector pIVETP (Rainey, 1999) with the Tc-resistance gene removed. Plasmid pIVET-Tc4 was mobilized into P. fluorescens SBW25 by conjugation with the help of pRK2013 $\left(\mathrm{Tra}^{+}\right)$. Integration by single homogeneous recombination was selected on M9 plates supplemented with CFC, Tc and X-Gal $\left(40 \mu \mathrm{g} \mathrm{ml}^{-1}\right)$. Allelic-exchange mutants were selected as previously described (Gal et al., 2003) by growing the purified transconjugant for two successive $24 \mathrm{~h}$ periods in LB broth without antibiotic selection. The mutant SBW25Tc (SBW25:: res1-tet-res1) was confirmed by the loss of the plasmid-encoded Pc resistance.

Transcriptional hut RIVET fusion plasmids were generated from pIVET5, which contained the wild-type $\operatorname{tnp} R$ reporter, and its two derivatives with a modified $\operatorname{tnpR}$ ribosome-binding site (RBS) $\left(t n p R^{\text {mut168}}, t n p R^{\text {mut135}}\right)$ (Lee et al., 1999). The plasmid vectors were firstly modified by replacing the lac $Z$ gene with a $\mathrm{Km}$-resistance cassette, which was later used as a selective marker for plasmid conjugation. The $\mathrm{Km}^{\mathrm{r}}$ cassette was obtained from pUC4K (accession no. X06404) by PCR amplification using primers $4 \mathrm{KF}$ and $4 \mathrm{KR}$ (Table 1). A KpnI restriction site was incorporated into the PCR primers to facilitate cloning into pIVET5 and its two derivatives, to generate $\mathrm{p} 674 \mathrm{Km}, \mathrm{p} 675 \mathrm{Km}$ and $\mathrm{p} 676 \mathrm{Km}$. The $2.47 \mathrm{~kb}$ hut fragment was then cloned into the BglII site of these three plasmids to generate the final constructs p674Km-hutT, p675Km-hutT and p676Km-hutT, which have the hutT gene fused to $\operatorname{tn} p R^{\mathrm{wt}}, \operatorname{tn} p R^{\mathrm{mut} 168}$ and $\operatorname{tn} p R^{\mathrm{mut135}}$, 
Table 1. Bacterial strains, plasmids and oligonucleotide primers used in this study

\begin{tabular}{|c|c|c|}
\hline $\begin{array}{l}\text { Strain, plasmid } \\
\text { or primer }\end{array}$ & Relevant characteristics & Source or reference \\
\hline \multicolumn{3}{|l|}{ P. fluorescens } \\
\hline SBW25 & Wild-type strain isolated from phyllosphere of sugar beet & Rainey \& Bailey (1996) \\
\hline SBW25 $\Delta h u t T$ & hut $T$ deletion mutant of SBW25 & $\begin{array}{l}\text { X.-X. Zhang \& P. B. Rainey, } \\
\text { unpublished results }\end{array}$ \\
\hline SBW25-lacZ & SBW25 carrying lac $Z$ in a phage locus & $\begin{array}{l}\text { X.-X. Zhang \& P. B. Rainey, } \\
\text { unpublished results }\end{array}$ \\
\hline SBW25Tc & SBW25: : res1-tet-res1 & This work \\
\hline PI122 & IVET fusion strain for pIVETP : hut $T$ & Rainey (1999) \\
\hline \multicolumn{3}{|l|}{ E. coli } \\
\hline DH5 $\alpha \lambda$ pir & supE44 $\Delta$ lacU169 hsdR17, recA1 endA1 gyrA96 thi-1 relA1, ipir & Hanahan (1983) \\
\hline \multicolumn{3}{|l|}{ Plasmid } \\
\hline pRK2013 & Helper plasmid, $\mathrm{Tra}^{+}, \mathrm{Km}^{\mathrm{r}}$ & Ditta et al. (1980) \\
\hline pUIC3 & Universal IVET vector with 'lacZ, $\mathrm{Mob}^{+}, \mathrm{Tc}^{\mathrm{r}}$ & Rainey (1999) \\
\hline pIVETP & IVET vector with 'panB'lacZ, oriR6K, $\mathrm{Mob}^{+}, \mathrm{Tra}^{-}, \mathrm{Pc}^{\mathrm{r}}, \mathrm{Tc}^{\mathrm{r}}$ & Rainey (1999) \\
\hline pIVETP1 & Derivative of pIVETP without the $\mathrm{Tc}^{\mathrm{r}}$ gene & This work \\
\hline $\mathrm{pUIC} 3 \Delta h u t T$ & pUIC3 containing hut $T$ deletion fragment, $\mathrm{Tc}^{\mathrm{r}}$ & This work \\
\hline pGH436 & pBR322:: res1-tet-res $1, \mathrm{Ap}^{\mathrm{r}}, \mathrm{Tc}^{\mathrm{r}}$ & Stark et al. (1991) \\
\hline pAS232 & pBluescript containing $2 \cdot 5 \mathrm{~kb} K p n \mathrm{I}-P s t \mathrm{I}$ fragment from SBW25 & Spiers et al. (2002) \\
\hline pIVET-Tc4 & $\begin{array}{l}\text { pIVETP1 carrying the res1-tet-res } 1 \text { cassette in the middle of } 2.5 \mathrm{~kb} \\
\text { fragment from pAS } 232\end{array}$ & This work \\
\hline pIVET5 & RIVET vector with 'tnpR $R^{\mathrm{wt} \prime} l a c Z Y$, ori $6 \mathrm{~K}, \mathrm{Mob}^{+}, \mathrm{Tra}^{-}, \mathrm{Ap}^{\mathrm{r}}$ & Camilli \& Mekalanos (1995) \\
\hline p $674 \mathrm{Km}$ & Derivative of pIVET5, lacZY was replaced with $\mathrm{Km}^{\mathrm{r}}$ gene & This work \\
\hline $\mathrm{p} 675 \mathrm{Km}$ & Derivative of pIVET5 with $\operatorname{tnp} R^{\text {mut168}}$, lacZY was replaced with $\mathrm{Km}^{\mathrm{r}}$ gene & This work \\
\hline p676Km & Derivative of pIVET5 with $\operatorname{tnp} R^{\text {mut135 }}$, lacZY was replaced with $\mathrm{Km}^{\mathrm{r}}$ gene & This work \\
\hline p674Km-hutT & p674Km carrying $2 \cdot 47 \mathrm{~kb}$ hut fragment, hutT:: $\operatorname{tnp} R^{\mathrm{wt}}$ fusion & This work \\
\hline p $675 \mathrm{Km}-h u t T$ & p675Km carrying $2 \cdot 47 \mathrm{~kb}$ hut fragment, hutT::tnp $R^{\text {mut } 168}$ fusion & This work \\
\hline p676Km-hutT & p676Km carrying $2 \cdot 47 \mathrm{~kb}$ hut fragment, hutT:: $\operatorname{tnp} R^{\text {mut135 }}$ fusion & This work \\
\hline \multicolumn{3}{|l|}{ Primers $^{\star}$} \\
\hline $4 \mathrm{KF}$ & 5'-GGGGTACCCCTTTCCCAGTCACGACGTTGT-3' & This work \\
\hline $4 \mathrm{KR}$ & 5'-GGGGTACCCCACAGGAAACAGCTATGACCA-3' & This work \\
\hline PhutT-1F & 5'-GAAGATCTCGCTGATGATGGACAAG-3' & \\
\hline PhutT-1R & 5'-cagcatgcgatcgttgacggaGACCGGGTTGTGCACGGCCAT-3' & This work \\
\hline PhutT-2F & 5'-tccgtcaacgatcgcatgctgGGTGCCGTGTGGATCGTG-3' & This work \\
\hline PhutT-2R & 5'-GAAGATCTGTAACGCGCCGCGAGGCTG-3' & This work \\
\hline
\end{tabular}

${ }^{\star}$ Restriction sites incorporated into the primers are underlined. Random complementary sequences designed for the SOE-PCR are shown in lower-case type.

respectively. They were transferred into $P$. fluorescens SBW25Tc by conjugation with the help of pRK2013. Transconjugants were selected on M9 plates supplemented with $\mathrm{Km}$, Tc and half-strength CFC.

Deletion of the hut T was achieved via splicing by overlapping extension using the polymerase chain reaction (SOE-PCR; Horton et al., 1989) in conjunction with a two-step allelic exchange strategy, as previously described (Gal et al., 2003). Briefly, DNA fragments ( $~ 900 \mathrm{bp}$ ) flanking both sides of the hut T were amplified from SBW25 cells by using the two primer pairs PhutT-1F/PhutT-1R and PhutT-2F/PhutT2R (Table 1). The two DNA fragments were then ligated together by a third PCR reaction using primers PhutT-1F and PhutT-2R. This was possible because of the complementary sequences incorporated into primers PhutT-1R and PhutT-2F (Table 1). The resulting $1.8 \mathrm{~kb}$ fragment was first cloned into pCR8 (Invitrogen) and the nucleotide sequence obtained. The fragment was then cloned into the integration vector pUIC3 at the unique BglII restriction site to generate
pUIC3 3 hutT. To construct the hut T deletion mutant of SBW25, plasmid pUIC3 3 hut T was mobilized into P. fluorescens SBW25 by conjugation with the help of pRK2013. Integration into the chromosome by a single homogeneous recombination event was selected for on LB agar containing nitrofurantoin $\left(100 \mu \mathrm{g} \mathrm{ml}^{-1}\right)$, Tc and X-Gal. To select for allelic exchange mutants, single blue-coloured transconjugants were grown for two successive $24 \mathrm{~h}$ periods in LB broth without antibiotic selection. The bacterial cells were plated on LB agar containing X-Gal. White $\mathrm{Tc}^{\mathrm{s}}$ colonies were checked for loss of hut T by PCR amplification using primers PhutT-1F and PhutT-2R.

Enzyme assays. In experiments that identified histidine as the inducer, $\beta$-galactosidase activities were measured by the standard Miller assay (Miller, 1972) and values were expressed as Miller units. Other $\beta$-galactosidase activities were assayed using a more sensitive method that uses 4 -methylumbelliferyl- $\beta$-D-galactoside (4MUG) as the enzymic substrate. The product (7-hydroxy-4-methylcoumarin, 
4MU) was detected in a Hoefer DyNA Quant 200 fluorometer (Pharmacia Biotech) following the manufacturer's instructions. The reaction was monitored at $460 \mathrm{~nm}$ with an excitation wavelength of $365 \mathrm{~nm}$. The enzyme activity was expressed as aM 4MU $\min ^{-1}$ cell $^{-1}$

For in vitro growth assays of the TnpR activities, the hutT::tnpR fusions were first cultivated in LB broth containing Tc $\left(10 \mu \mathrm{g} \mathrm{ml}^{-1}\right)$. The overnight culture was washed once with sterile distilled water to remove the antibiotic and then $10 \mu \mathrm{l}\left(\sim 10^{6}\right.$ cells $)$ was inoculated into $10 \mathrm{ml} \mathrm{M} 9$ broth with and without inducer. The level of resolution was measured by plating onto M9 plus Km plates for single colonies. $\mathrm{Tc}^{\mathrm{s}}$ strains were identified by replica-plating the colonies onto M9 plates containing $10 \mu \mathrm{g} \mathrm{Tc} \mathrm{ml}{ }^{-1}$. Approximately 300 colonies were counted for each treatment.

Plant experiments. Coated seeds of sugar beet (Beta vulgaris var. Amethyst) were germinated and cultivated as previously described (Rainey, 1999) in $5 \mathrm{ml}$ scintillation vials using non-sterile vermiculite as a growth substrate. For experiments testing expression of RIVET fusions, the inoculants were prepared by growing $h u t T:: \operatorname{tnp} R$ fusion strains in M9 broth with Tc, and the overnight cultures were washed in sterile distilled water. About $10^{3}$ bacterial cells were inoculated onto each seed. Bacteria from the shoot and rhizosphere (roots with attached vermiculite) were recovered on plates of M9 supplemented with $\mathrm{Km}$ and half-strength CFC. The proportion of $\mathrm{Tc}^{\text {s }}$ c.f.u. was measured subsequently by replicaplating the colonies onto M9 plates supplemented with Tc.

Plant extracts used in this study were prepared from the shoot of a onemonth-old pot-grown sugar beet. Twenty grams were cut and put into a $50 \mathrm{ml}$ plastic tube containing glass beads and $10 \mathrm{ml}$ distilled water. After vortex-mixing at the highest speed for $10 \mathrm{~min}$, the supernatant was filter-sterilized. The extract was used at one-tenth strength in minimal M9 medium.

The plant competitive colonization assay was carried out with 10 independent cultures. To ensure that strains in competition were physiologically equal, both the mutant (SBW25 $\Delta h u t T$ ) and the wildtype competitor (SBW25-lacZ) were inoculated directly, employing bacteria that had been stored at $-80{ }^{\circ} \mathrm{C}$, grown in LB broth, and then subcultured once in M9 broth. To initiate the competition, mutant and wild-type from overnight M9 cultures were mixed equally and then washed once in sterile water. The bacterial suspensions were used to inoculate sugar beet seeds as previously described (Rainey, 1999), and initial frequencies of competing strains were determined by dilution plating onto LB plus X-Gal plates. Two weeks after sowing, plants were harvested, and frequencies of the mutant and the wild-type competitor were counted on M9 plates supplemented with half-strength CFC and $\mathrm{X}-\mathrm{Gal}$. The initial and final frequencies were then used to calculate the selection rate constant (SRC), which expresses the amount of change in competitive performance relative to the wild-type (Lenski, 1991). In order to factor out any effect of the lac $Z$ marker gene on competitive performance, competition experiments were performed between SBW25-lacZ and the ancestral SBW25 as a control.

\section{RESULTS}

\section{rhi14 is histidine inducible and required for histidine utilization}

In order to tailor the RIVET strategy for $P$. fluorescens it was necessary to identify a $P$. fluorescens locus that was plant inducible, ideally in response to a stimulus that could be applied in the laboratory. A search for likely candidates among previously isolated rhi fusions revealed rhil4 (in fusion strain PI122), which shows significant similarity to both the histidine transport gene (hutT) of Pseudomonas putida and the proline transport gene (proY) of enteric bacteria (Rainey, 1999).

To test whether rhily is amino acid responsive, the fusion strain PI122 was grown overnight in minimal medium (M9) in the presence of $10 \mu \mathrm{g}$ Casamino acids $\mathrm{ml}^{-1}$, and $\beta$-galactosidase activity determined using the chromosomeintegrated promoterless lac $Z$ reporter carried in the IVET vector (Rainey, 1999). rhil4 showed an approximately $2 \cdot 5$ fold induction compared to the same strain grown in M9 without Casamino acids (data not shown), prompting a more precise analysis of inducing conditions. Fig. 1 shows the response of rhil4 to five biochemically diverse amino acids (histidine, proline, arginine, aspartate and tryptophan). Only histidine was able to activate transcription of promoterless lac $Z$ in the PI122 fusion strain. Further analysis showed that induction by histidine was both dose and time dependent (data not shown).

With the genome sequence of $P$. fluorescens SBW25 now available, the genomic context of rhil4 was ascertained (http://www.sanger.ac.uk/Projects/P_fluorescens). As shown in Fig. 2, rhil4 is hutT, one of 12 genes that are organized in the same orientation and encode enzymes with predicted roles in histidine utilization $(h u t)$. IVET fusion strain PI122 contains a transcriptional fusion between hut $T$ and the promoterless 'panB' lacZ genes of pIVETP (Rainey, 1999). The fusion junction is at the 111th nucleotide from the ATG start of hutT. In silico analysis of the hut genes shows that the histidine-responsive promoter is located in front of hutU: expression of the hut genes in Pseudomonas is known to be controlled by the HutC repressor (Hu et al., 1989). Details of the locus are shown in Fig. 2.

To obtain experimental evidence for a functional role of hut $T$ in histidine utilization, an in-frame deletion mutant of

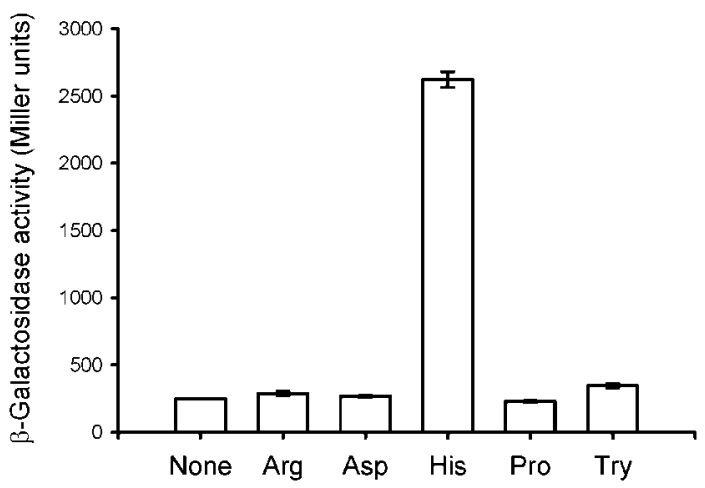

Fig. 1. Transcriptional response of the IVET fusion PI122 to amino acids. $\beta$-Galactosidase activities were measured for cells growing in minimal medium M9 with the addition of the indicated individual amino acids at $15.5 \mathrm{\mu g} \mathrm{ml}^{-1}$. Data are means and standard errors of six replicates. 


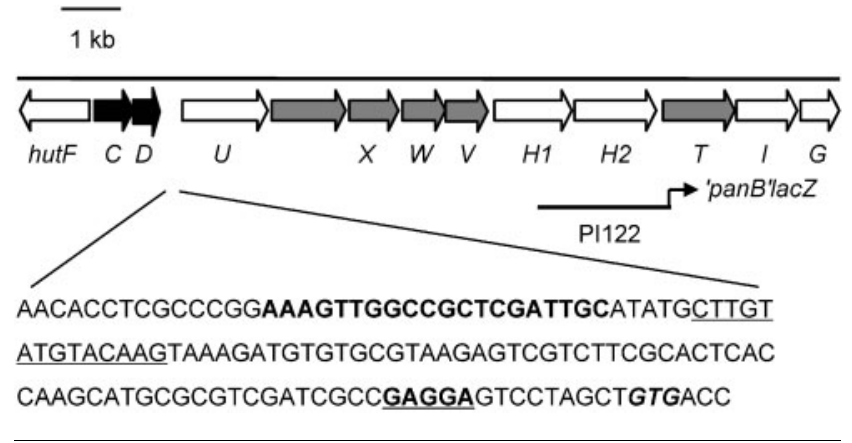

Fig. 2. Genetic organization of the histidine utilization (hut) locus of $P$. fluorescens SBW25 based on the $P$. fluorescens SBW25 genome sequence (http://www.sanger.ac.uk). The metabolic genes are shown in empty arrow bars and the putative transporters are shown in grey arrow bars. The hut genes are regulated by genes encoding HutC(D) that are represented by black arrow bars. The $2.47 \mathrm{~kb}$ insert of the original IVET fusion (PI122) and its orientation are indicated by an arrowed line (accession no. AJ421809). It spanned the last $550 \mathrm{nt}$ of hutH1, all of hutH2, and through the first 111 nt of hutT. The start code of hut $U$ and the RBS sequence are shown in bold italic and bold underlined type, respectively. The putative HutC repressor binding site ( $\mathrm{Hu}$ et al., 1989) is underlined and the predicted $\delta^{54}$-specific promoter sequence is indicated by bold type.

hut T was generated by allelic exchange. If the function of this gene is histidine utilization, then a deletion mutant should not be able to grow on histidine as a sole carbon and nitrogen source. As expected, SBW25 $\Delta h u t T$ grew normally on minimal M9 medium with glucose and ammonia and on minimal M9 with proline as a sole carbon and nitrogen source, but was incapable of growth when histidine was the sole carbon and nitrogen source (the wild-type grew normally on minimal M9 medium with histidine as a sole carbon and nitrogen source). A full description of the regulation, function and organization of this operon in SBW25 will be published elsewhere.

\section{Application of RIVET to P. fluorescens SBW25}

The RIVET strategy comprises two components: (1) a suicide integration vector pIVET5 (Camilli \& Mekalanos, 1995) containing a promoterless version of $\operatorname{tnp} R$, which encodes the site-specific recombinase, resolvase, from $\operatorname{Tn} \gamma \delta$; (2) a res1-tet-res1 cassette, which is the substrate for the recombinase. When $\operatorname{tn} p R$ is expressed in a strain containing the artificial resolvase substrate cassette, excision (resolution) of the Tc gene occurs, resulting in $\mathrm{Tc}^{\mathrm{s}}$ daughter cells.

Development of the RIVET strategy for $P$. fluorescens SBW25 began with modification of pIVET5: promoterless lac $Z Y$ was replaced with a $\mathrm{Km}$-resistance cassette to provide a selectable marker for conjugation. Next, the res1-tet-res1 cassette was integrated into the $P$. fluorescens SBW25 genome by double homologous recombination (see Methods). The
$2 \cdot 47 \mathrm{~kb}$ hut gene fragment from IVET fusion PI122 was then introduced into the $\mathrm{Km}$-resistance derivative of pIVET5 immediately upstream of the promoterless recombinase. Finally, the completed hut::tnpR fusion plasmid was introduced into $P$. fluorescens SBW25::res1-tet-res1 by conjugation in which integration by single homologous recombination was selected by screening for Km resistance.

To check whether the recombinase was functional in $P$. fluorescens and capable of resolving the $\mathrm{Tc}^{\mathrm{r}}$ marker in the restet-res 1 cassette, the hut-tnpR fusion strain was grown overnight in minimal M9 medium in the presence and absence of $100 \mu \mathrm{g}$ histidine $\mathrm{ml}^{-1}$. The following morning the cultures were diluted and the cells plated on minimal M9 medium. Approximately 300 colonies from each treatment were replica-plated onto minimal M9 medium containing $\mathrm{Tc}$ to determine the frequency of $\mathrm{Tc}^{\mathrm{s}}$ colonies. The majority of colonies $(>90 \%)$ from populations grown in the presence of the histidine inducer were $\mathrm{Tc}^{\mathrm{s}}$. However, a similar proportion of cells grown in the absence of the inducer were also $\mathrm{Tc}^{\mathrm{s}}$. This result showed that while the recombinase was active in $P$. fluorescens, it was too sensitive to be of general use.

Previous work (Lee et al., 1999) has shown that activity of the recombinase needs to be 'tuned' to the strength of the promoter under study; tuning being achieved by modification of the RBS of the resolvase. Given that resolution of the Tc cassette occurred in more than $90 \%$ of the cells carrying the $h u t-t n p R$ fusion, even in the absence of histidine, a less efficient RBS was required. We therefore took advantage of two derivatives of pIVET5 that contain modifications of the RBS of the $\operatorname{tn} p R$ gene: $\operatorname{tnp} R^{\mathrm{mut168}}$ and $\operatorname{tn} R^{\mathrm{mut135}}$. In $V$. cholerae, both $\operatorname{tn} p R^{\text {mut168 }}$ and $\operatorname{tn} p R^{\text {mut135 }}$ cause a reduction in the translational efficiency of $\operatorname{tn} p R$ (Lee et al., 1999). Into both $\operatorname{tn} p R^{\text {mut168 }}$ and $\operatorname{tn} p R^{\text {mut135 }}$ we cloned the $2.47 \mathrm{~kb}$ hut fragment upstream of the modified $\operatorname{tn} p R$ and then introduced each into $P$. fluorescens by conjugation and homologous recombination. Modified strains were grown overnight in the presence or absence of $100 \mu \mathrm{g}$ histidine $\mathrm{ml}^{-1}$ and the ratio of $\mathrm{Tc}^{\mathrm{s}}$ to $\mathrm{Tc}^{\mathrm{r}}$ was determined by replicaplating. In the presence of histidine, $\sim 45 \%$ of cells carrying the hut $T:: \operatorname{tnp} R^{\text {mut168 }}$ fusion were $T c^{\mathrm{s}}$, whereas all colonies carrying the hutT:: $\operatorname{tn} p R^{\text {mut135 }}$ fusion retained their $\mathrm{Tc}^{\mathrm{r}}$ phenotype. No $\mathrm{Tc}^{\mathrm{s}}$ cells were detected in the absence of histidine.

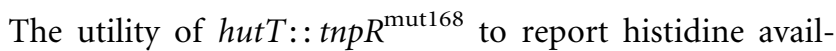
ability was more rigorously examined by determining its responsiveness to histidine concentrations spanning four orders of magnitude. In parallel, we examined the histidine responsiveness of an isogenic strain carrying a hutT: : lac Z fusion. The correspondence between the responses of the two reporters (promoterless $t n p R$ and lacZ) to increasing doses of histidine was highly comparable (Fig. 3). A similar experiment examining the response of the two reporter strains to $500 \mu \mathrm{g}$ histidine $\mathrm{ml}^{-1}$ over an $8 \mathrm{~h}$ period also yielded highly similar time-response curves (Fig. 4). These data demonstrate the utility of the RIVET strategy in $P$. 


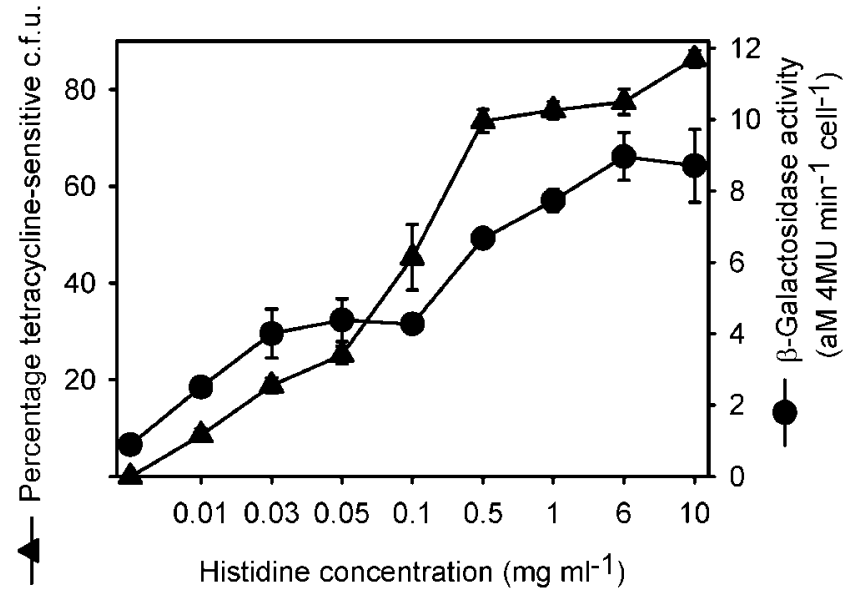

Fig. 3. Effect of histidine concentration on hutT gene transcriptional fusions to the reporter genes of tnp $R^{\text {mut168 }}$ (SBW25TC::p675Km-hutT) and lacZY (IVET fusion PI122), respectively. Data are means and standard errors of three replicates.

fluorescens. They also show that the level of resolution is dependent on the strength of the inducing signal.

\section{hutT activity in the plant environment}

With the hut $T:: \operatorname{tnp} R^{\text {mut168 }}$ fusion providing a simple means of reporting the response of the hut locus to histidine, we applied the fusion strain to the plant environment to see whether it was possible to measure hut T gene activity in a more complex system. The hut $T:: \operatorname{tn} p R^{\text {mut168 }}$ fusion strain was inoculated onto sugar beet seedlings $\left(\sim 10^{3}\right.$ cells per seed), which were allowed to germinate and grow in vermiculite (neither the seed nor the vermiculite was sterilized). The same fusion was also propagated in vermiculite devoid of seedlings and on seedlings that were watered on day 0 and day 10 with $5 \mathrm{ml}$ and $3 \mathrm{ml}$ of a $10 \mu \mathrm{g} \mathrm{ml}^{-1}$ solution

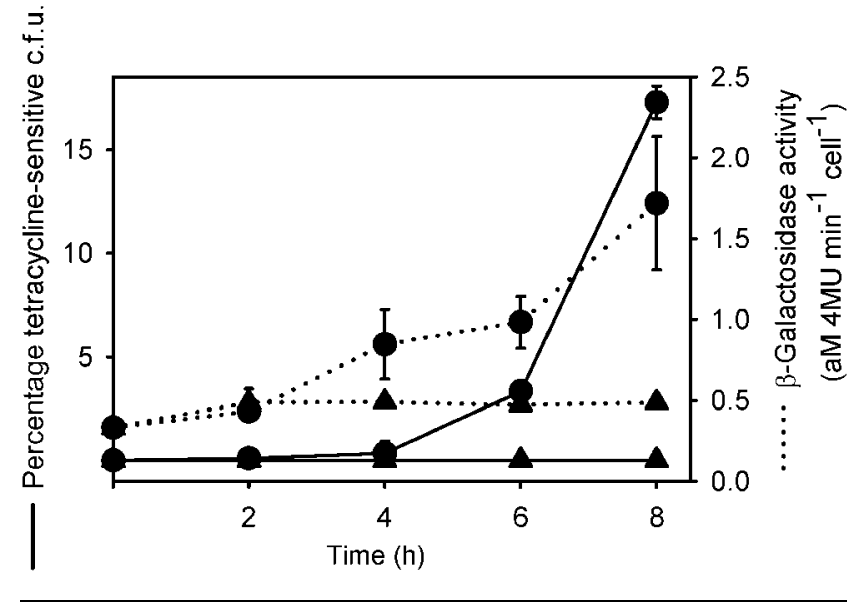

Fig. 4. Time-course of histidine induction of the hutT gene, as measured via transcriptional fusions to the promoterless reporter genes tnp $R^{\text {mut168 }}$ (SBW25Tc::p675Km-hutT) and lacZ (IVET fusion PI122), represented by solid and discontinuous lines, respectively. The transcriptional activation was determined in M9 broth $(\boldsymbol{\Delta})$ and $\mathrm{M} 9$ broth containing $500 \mu \mathrm{g}$ histidine $\mathrm{ml}^{-1}$ (๑). Data are means and standard errors of three replicates.

of histidine, respectively. A control fusion was also included in which the $2.47 \mathrm{~kb}$ hut fragment was cloned in the opposite (reverse) orientation with respect to the promoterless recombinase. After 2 weeks, $P$. fluorescens cells were recovered from both the rhizosphere and the shoot, and a minimum of 300 colonies from each treatment were replicaplated to check for resolution of the res1-tet-res1 cassette. The results are shown in Table 2 and provide evidence of low, but detectable, levels of recombinase activity (indicative of hutT activation) in both the rhizosphere and phyllosphere. Activation of hutT was also detected in plant extract. No resolution of the res1-tet-res 1 cassette was detected in the vermiculite-only (no seedling) control; similarly, no resolution of the res1-tet-res 1 cassette was detected in the fusion

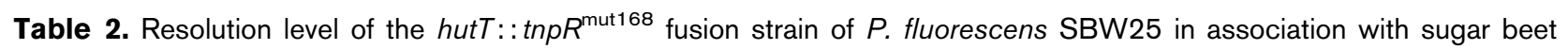

Data are means and standard errors from the combined total of bacteria from between one and three plants, from three independent experiments. Raw data are given in parentheses: total number of $\mathrm{Tc}^{\mathrm{s}}$ colonies as a fraction of the total number of colonies counted.

\begin{tabular}{|c|c|c|}
\hline \multirow[t]{2}{*}{ Treatment $^{*}$} & \multicolumn{2}{|c|}{ Percentage of $\mathrm{Tc}^{\text {s }}$ c.f.u. } \\
\hline & Shoot & Rhizosphere \\
\hline $\begin{array}{l}\text { Control: seed inoculation of hutT:: } \operatorname{tnp} R^{\text {mut } 168} \text {, fusion } \\
\text { strain with wrong insertion direction }\end{array}$ & $0 \pm 0(0 / 2146)$ & $0 \pm 0(0 / 3104)$ \\
\hline $\begin{array}{l}\text { Control: seed inoculation of hutT:: } \operatorname{tnp} R^{\text {mut168}} \text {, fusion } \\
\text { strain with addition of histidine }\left(10 \mu \mathrm{g} \mathrm{ml}^{-1}\right)\end{array}$ & $1 \cdot 32 \pm 0 \cdot 08(12 / 916)$ & $4 \cdot 68 \pm 2 \cdot 41(52 / 1324)$ \\
\hline Induction by plant extract & $1 \cdot 22 \pm 0 \cdot 40(15 / 1239)$ & - \\
\hline
\end{tabular}

${ }^{\star}$ ANOVA shows highly significant differences among treatments $(P<0 \cdot 0009)$. 
strain containing the $2.47 \mathrm{~kb}$ hut fragment in the reverse orientation. While the level of induction was low, ANOVA shows a highly significant effect $(P<0 \cdot 0009)$.

Taking advantage of the data presented in Fig. 3, which show the relationship between histidine concentration and resolution of the resl-tet-resl cassette, it is possible to estimate the concentration of histidine present in the plant environment (as sensed by SBW25): 0.39\% resolution in the rhizosphere (Table 2) corresponds to approximately $0 \cdot 6 \mu \mathrm{g}$ histidine $\mathrm{ml}^{-1}(3 \mu \mathrm{M})$.

\section{Ecological significance of histidine for bacterial colonization in planta}

Having demonstrated the availability of histidine in the plant environment, we next asked whether histidine plays a significant role in bacterial colonization in planta. To do this we examined the competitive ability of SBW25 $\Delta h u t T$ relative to the wild-type strain during the course of colonization of sugar beet seedlings.

SBW25 $\Delta$ hutT was mixed 1:1 with a lacZ-marked wild-type strain (SBW25-lacZ; X.-X. Zhang \& P. B. Rainey, unpublished results) and the mixed bacteria were inoculated onto sugar beet seeds. Two weeks after inoculation, the plants were destructively harvested and the ratio of mutant to the wild-type competitor was determined by plating on M9 plates supplemented with X-Gal. As a control for any effect due to the lac $Z$ marker, ancestral wild-type SBW25 was competed in parallel against SBW25-lacZ. The results, presented in Fig. 5, show no significant difference between the fitness of the mutant relative to the competitor (SBW25lacZ), or between the fitness of the ancestral wildtype SBW25 relative to SBW25-lacZ. In other words, SBW25 $\Delta$ hut T is not compromised in its ability to colonize sugar beet seedlings.

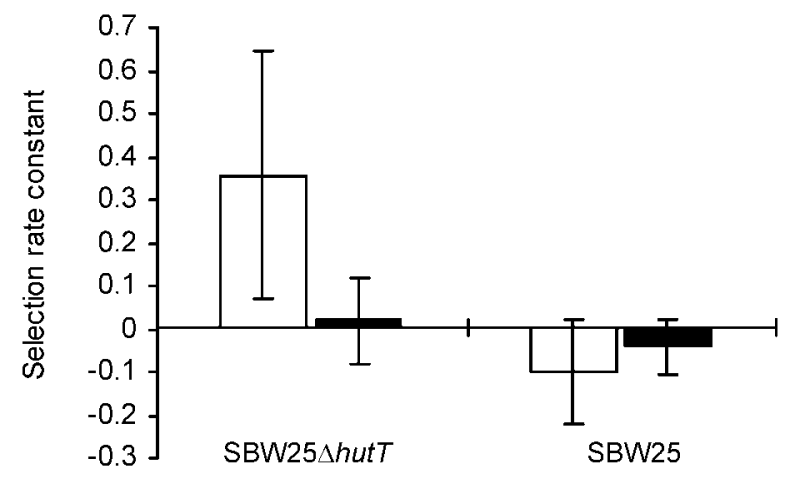

Fig. 5. Fitness of $P$. fluorescens SBW25 $\Delta$ hutT and ancestral $P$. fluorescens SBW25 (wild-type) relative to a lacZ-marked strain of $P$. fluorescens SBW25-lacZ. White and black bars refer to fitness in the shoot and rhizosphere, respectively. Data are means and standard errors of 10 plants inoculated with independent cultures. ANOVA analysis showed no significant difference among means.

\section{DISCUSSION}

Here we have described the development and use of the RIVET strategy in P. fluorescens SBW25 to monitor hut gene activity in vitro and in planta. Central to this work was a rhizosphere-inducible locus isolated in a previous study and predicted, on the basis of in silico analyses, to be involved in histidine uptake and metabolism and thus to be histidine responsive. This prediction was confirmed by showing that the locus is responsive, at a transcriptional level, to histidine. Moreover, analysis of SBW25 $\Delta$ hutT confirmed that the locus identified by IVET fusion strain PI122 plays a functional role in histidine utilization: on the basis of its similarity to the HutT transporter of $P$. putida and Pseudomonas aeruginosa (Rietsch et al., 2004) it is highly likely to function as a histidine-specific transporter.

Armed with the knowledge that the hut locus is histidine inducible, we proceeded to apply the RIVET strategy in $P$. fluorescens. Initial trials using the native pIVET5 plasmid (although with a Km-resistance cassette substituting for the lac $Z$ reporter) showed the system to be too sensitive to be useful. Subsequent analysis of two alternative plasmids containing modified $\operatorname{tn} p R$ RBSs showed that the activity of $\operatorname{tn} p R$ when controlled by the $\operatorname{tn} p R^{\text {mut168 }}$ RBS closely matched the transcriptional activity of the hut locus. Moreover, the response to histidine (across both dose and time) as reported by $\operatorname{tnpR}$ closely paralleled the response as reported by lacZ.

To demonstrate the utility of the strategy and to verify previous claims that the hut locus is rhizosphere inducible (Rainey, 1999), the recombinase reporter was used to measure the activity of hut T in the plant (including rhizosphere) environment. Evidence of low, albeit significant, induction was obtained in the rhizosphere, the phyllosphere and in plant extract. The fact that no induction was detected when the hut $T$ fusion strain was propagated in vermiculite alone indicates that the inducing signal(s) is plant-derived.

The dose-response curve (Fig. 3) relating histidine concentration to recombinase activity was used to obtain an approximate estimate of the concentration of histidine in the plant environment $(3 \mu \mathrm{M})$. Interestingly, this estimate is identical to the concentration of histidine reported in root exudates from tomato seedlings (Simons et al., 1997); however, it is based on the assumption that histidine is the sole inducer of hutT in the plant environment. In P. putida, urocanate (the first breakdown product of histidine) is also able to induce transcription of hut (Hu et al., 1989); however, urocanate is not known to occur in the plant environment and is likely to occur solely within bacterial cells as a consequence of the uptake of histidine from the environment and metabolism in vivo.

While our results add to the growing list of successful RIVET applications (Casavant et al., 2002, 2003; Lee et al., 1998, 1999; Camilli \& Mekalanos, 1995), it is worth noting that the graded dose-response curve seen in this study, 
which mirrors those reported elsewhere, is counter-intuitive. Graded responses are expected when transcriptional activity is reported at a population level via an enzyme, such as $\beta$-galactosidase, in which the input signal causes a proportional response in output (transcription and enzyme activity). Recombinase reporters ought, in principle, to generate allor-nothing (threshold) responses: resolution of the res1-tetres 1 cassette requires a certain minimal threshold concentration of recombinase before cells resolve the Tc-resistance gene. Assuming that all cells experience the same environment (as in a shaken broth culture), then resolution should occur in all cells at approximately the same time. The implication is that at the single-cell level, the sensing and response of individual cells to specific signals are highly variable, despite apparent environmental uniformity, a result that we have independently verified using $g f p$ reporter fusions to hut (X.-X. Zhang \& P. B. Rainey, unpublished results). Clearly, the response of individual cells to identical levels of inducer is not reproducible at the single-cell level, and suggests a strong probabilistic element to regulatory networks consistent with a number of recent reports (McAdams \& Arkin, 1997; Fiering et al., 2000; Leveau \& Lindow, 2001; Elowitz et al., 2002). One additional value of recombinase-based reporter strategies may be to provide insights into the balance between stochastic and deterministic processes that control gene regulation.

The inability of the hutT mutant to utilize histidine as a sole carbon and nitrogen source confirms that the biological function of the hut operon is uptake and degradation of histidine. Activation of hut T transcription in the plant environment (in response to plant signals) strongly suggests that histidine is present and available in this environment and can be used as a source of carbon and/or nitrogen by SBW25. The fact that there is no competitive difference between a mutant defective in its ability to utilize an exogenous source of histidine and the wild-type indicates that the ability to utilize histidine in the plant environment does not contribute significantly toward competitive fitness in this environment. This finding is not surprising, given both the oligotrophic nature of the rhizosphere (Poindexter, 1981 ) and the diverse nutritional capabilities of $P$. fluorescens (Stanier et al., 1966).

Taken together, our results demonstrate the utility of the recombinase strategy to report, in the plant environment, at the level of the single bacterial cell, transcriptional activity of a single locus in response to specific inducing signals. Further tailoring of the system, possibly via alterations in the translational activity of the recombinase or through modification of the sampling regime (for example, more samples from specific locations along the root) and by studies of the transcriptional activity of additional loci, stands to provide insight into the distribution of inducing signals in complex environments. Such insights into environmental complexity are consistent with those provided by the use of recombinase reporters to study gene expression in $V$. cholerae in mammalian systems (Lee et al., 1999; Merrell \& Camilli, 2000) and, more recently, the availability of arabinose and toluene to Ent. cloacae JL1157 and P. fluorescens A506 in the plant environment (Casavant et al., 2002, 2003). They also complement green fluorescent protein (GFP)-based work that has demonstrated heterogeneity in the bioavailability of sugar (Leveau \& Lindow, 2001) and iron (Joyner \& Lindow, 2000), as well as indoleacetic acid metabolism, in epiphytic bacteria (Brandl et al., 2001).

\section{ACKNOWLEDGEMENTS}

We thank A. Camilli, Tufts University School of Medicine, Boston, MA, for providing the original RIVET plasmids used in this study. Preliminary sequence data used for the hut locus were obtained from the P. fluorescens SBW25 Sequencing Group at the Sanger Institute (http://www.sanger.ac.uk). This work was supported by NERC (UK).

\section{REFERENCES}

Brandl, M. T., Quinones, B. \& Lindow, S. E. (2001). Heterogeneous transcription of an indoleacetic acid biosynthetic gene in Erwinia herbicola on plant surfaces. Proc Natl Acad Sci U S A 98, 3435-3459.

Camilli, A. \& Mekalanos, J. J. (1995). Use of recombinase gene fusions to identify Vibrio cholerae genes induced during infection. Mol Microbiol 18, 671-683.

Camilli, A., Beattie, D. T. \& Mekalanos, J. J. (1994). Use of genetic recombination as a reporter of gene expression. Proc Natl Acad Sci U S A 91, 2634-2638.

Casavant, N. C., Beattie, G. A., Phillips, G. J. \& Halverson, L. J. (2002). Site-specific recombination-based genetic system for reporting transient or low-level gene expression. Appl Environ Microbiol 68, 3588-3596.

Casavant, N. C., Thompson, D., Beattie, G. A., Phillips, G. J. \& Halverson, L. J. (2003). Use of a site-specific recombination-based biosensor for detecting bioavailable toluene and related compounds on roots. Environ Microbiol 5, 238-249.

Ditta, G., Stanfield, S., Corbin, D. \& Helinski, D. R. (1980). Broad host range DNA cloning system for Gram negative bacteria: construction of a gene bank of Rhizobium meliloti. Proc Natl Acad Sci U S A 77, 7347-7351.

Elowitz, M. B., Levine, A. J., Siggia, E. D. \& Swain, P. S. (2002). Stochastic gene expression in a single cell. Science 297, 1183-1186.

Fiering, S., Whitelaw, E. \& Martin, D. I. K. (2000). To be or not to be active: the stochastic nature of enhancer action. BioEssays 22, 381-387.

Gal, M., Preston, G. M., Massey, R. C., Spiers, A. J. \& Rainey, P. B. (2003). Genes encoding a cellulose polymer contribute toward the ecological success of Pseudomonas fluorescens SBW25 on plant surfaces. Mol Ecol 12, 3109-3121.

Hanahan, D. (1983). Studies on transformation of Escherichia coli with plasmids. J Mol Biol 166, 557-580.

Horton, R. M., Hunt, H. D., Ho, S. N., Pullen, J. K. \& Pease, L. R. (1989). Engineering hybrid genes without the use of restriction enzymes: gene splicing by overlap extension. Gene 77, 61-68.

Hu, L., Allison, S. L. \& Phillips, A. T. (1989). Identification of multiple repressor recognition sites in the hut system of Pseudomonas putida. J Bacteriol 171, 4189-4195.

Joyner, D. C. \& Lindow, S. E. (2000). Heterogeneity of iron bioavailability on plants assessed with a whole-cell GFP-based bacterial biosensor. Microbiology 146, 2435-2445.

Lee, S. H., Angelichio, M. J., Mekalanos, J. J. \& Camilli, A. (1998). Nucleotide sequence and spatiotemporal expression of the 
Vibrio cholerae vieSAB genes during infection. I Bacteriol 180, 2298-2305.

Lee, S. H., Hava, D. L., Waldor, M. K. \& Camilli, A. (1999). Regulation and temporal expression patterns of Vibrio cholerae virulence genes during infection. Cell 99, 625-634.

Lenski, R. E. (1991). Quantifying fitness and gene stability in microorganisms. Biotechnology 15, 173-192.

Leveau, J. H. J. \& Lindow, S. E. (2001). Appetite of an epiphyte: quantitative monitoring of bacterial sugar consumption in the phyllosphere. Proc Natl Acad Sci U S A 98, 3446-3453.

Lindow, S. E. \& Brandl, M. T. (2003). Microbiology of the phyllosphere. Appl Environ Microbiol 69, 1875-1883.

McAdams, H. H. \& Arkin, A. (1997). Stochastic mechanisms in gene expression. Proc Natl Acad Sci U S A 94, 814-819.

Merrell, D. S. \& Camilli, A. (2000). Detection and analysis of gene expression during infection by in vivo expression technology. Philos Trans $R$ Soc Lond B 355, 587-599.

Miller, J. (1972). Experiments in Molecular Genetics. Cold Spring Harbor, NY: Cold Spring Harbor Laboratory.

Poindexter, J. S. (1981). Oligotrophy. Adv Microb Ecol 5, 63-89.

Preston, G. M., Bertrand, N. \& Rainey, P. B. (2001). Type III secretion in plant growth-promoting Pseudomonas fluorescens SBW25. Mol Microbiol 41, 999-1014.

Rainey, P. B. (1999). Adaptation of Pseudomonas fluorescens to the plant rhizosphere. Environ Microbiol 1, 243-257.

Rainey, P. B. \& Bailey, M. J. (1996). Physical and genetic map of the Pseudomonas fluorescens SBW25 chromosome. Mol Microbiol 19, 521-533.

Rainey, P. B. \& Preston, G. M. (2000). In vivo expression technology strategies: valuable tools for biotechnology. Curr Opin Biotechnol 11, 440-444.
Rietsch, A., Wolfgang, M. C. \& Mekalanos, J. J. (2004). Effect of metabolic imbalance on expression of type III secretion genes in Pseudomonas aeruginosa. Infect Immun 72, 1383-1390.

Sambrook, J., Fritsch, E. F. \& Maniatis, T. (1989). Molecular Cloning: a Laboratory Manual. Cold Spring Harbor, NY: Cold Spring Harbor Laboratory.

Simons, M., Permentier, H. P., de Weger, L. A., Wijffelman, C. A. \& Lugtenberg, B. J. J. (1997). Amino acid synthesis is necessary for tomato root colonization by Pseudomonas fluorescens strain WCS365. Mol Plant Microbe Interact 10, 102-106.

Spiers, A. J., Kahn, S. G., Bohannon, J., Travisano, M. \& Rainey, P. B. (2002). Adaptive divergence in experimental populations of Pseudomonas fluorescens. I. Genetic and phenotypic bases of wrinkly spreader fitness. Genetics 161, 33-46.

Spiers, A. J., Bohannon, J., Gerhrig, S. M. \& Rainey, P. B. (2003). Biofilm formation at the air-liquid interface by the Pseudomonas fluorescens SBW25 wrinkly spreader requires an acetylated form of cellulose. Mol Microbiol 50, 15-27.

Stanier, R. Y., Palleroni, N. J. \& Doudoroff, M. (1966). The aerobic pseudomonads: a taxonomic study. J Gen Microbiol 43, 159-271.

Stark, W. M., Grindley, N. D. F., Hatfull, G. F. \& Boocock, M. R. (1991). Resolvase-catalysed reactions between res sites differing in the central dinucleotide of subsite. EMBO J 10, 3541-3548.

Zhang, X.-X., Lilley, A. K., Bailey, M. J. \& Rainey, P. B. (2004a). The indigenous Pseudomonas plasmid pQBR103 encodes plant-inducible genes including three putative helicases. FEMS Microbiol Ecol 51, 9-17.

Zhang, X.-X., Lilley, A. K., Bailey, M. J. \& Rainey, P. B. (2004b). Functional and phylogenetic analysis of a plant-inducible oligoribonuclease (orn) gene from an indigenous Pseudomonas plasmid. Microbiology 150, 2889-2898. 